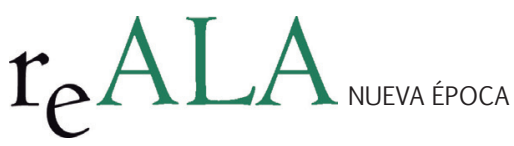

REALA, n 3, enero-junio 2015 ISSN: 1989-8975

DOI: http://dx.doi.org/10.24965/reala.voi3.10241

\title{
La elección directa del alcalde por los vecinos. Criterios para un régimen presidencialista en los gobiernos municipales
}

\author{
Joan Ridao i Martín \\ Profesor Titular Acreditado de Derecho Constitucional, Universidad de Barcelona \\ jridao@ub.edu \\ Alfons Garcia i Martínez \\ Economista \\ alfonsog@um.es
}

\section{Resumen}

Este trabajo explora las reformas necesarias, tanto en materia de legislación electoral como en la configuración institucional, para establecer un sistema presidencialista puro en los gobiernos municipales españoles, con una segregación de las elecciones para los concejales y para la alcaldía. Una modificación en este sentido consolidaría las tendencias, presentes en los sucesivos cambios que se han introducido en el régimen local, hacia una clara separación entre los dos órganos principales del gobierno municipal (plenario y alcaldía) y la gerencialización de su poder ejecutivo; por otro lado, daría respuesta a la reivindicación histórica de una elección directa, por parte de los vecinos, de la persona que debe ocupar la alcaldía de los municipios, lo cual se ajustaría a las crecientes aspiraciones sociales de incrementar los institutos de democracia directa. La hipótesis principal contemplada, la elección desdoblada de alcaldía y concejales, difiere considerablemente de las propuestas de reforma habitualmente planteadas en el sistema político español, por lo que el trabajo aborda también algunas dudas constitucionales sobre la cuestión.

Palabras clave

Gobiernos municipales, sistema electoral local, reformas electorales.

\section{Direct election of mayor by neighbors. Criteria for a presidential regime in Local Governments}

\section{Abstract}

This paper explores the necessary reforms, both in electoral legislation and institutional settings, to establish a pure presidential system in Spanish municipal governments, with a segregated election for councilors and mayor. A change in this regard consolidate trends present in the successive changes that have been introduced in the local government, to a clear separation between the two principal organs of the municipal government (plenary and mayor) and to increase its executive power; on the other hand, would address the historical claim of direct election by the neighbors of which person must occupy the mayor of the municipalities, which would conform to the growing social aspirations to increase the institutes of direct democracy. The main hypothesis contemplated, the splits election of mayor and councilors, differs considerably from the reform proposals usually raised in the Spanish political system, so that the work also addresses constitutional doubts on the matter.

\section{Keywords}

Local governments, local electoral system, electoral reforms. 
Sumario

\begin{abstract}
I. INTRODUCCIÓN. II. EL SISTEMA DE ELECCIÓN DE ALCALDES EN ESPAÑA: CONFIGURACIÓN ACTUAL Y REVISIÓN DE LAS PROPUESTAS PARA SU REFORMA. III. LA CONFIGURACIÓN INSTITUCIONAL DEL GOBIERNO MUNICIPAL Y SU INTERRELACIÓN CON EL RÉGIMEN ELECTORAL. IV. LA CONVENIENCIA DE UN RÉGIMEN PRESIDENCIALISTA EN EL GOBIERNO MUNICIPAL. V. ALGUNAS REFLEXIONES ADICIONALES SOBRE LAS REFORMAS LEGISLATIVAS NECESARIAS PARA LA ELECCIÓN DIRECTA DE LOS ALCALDES: 1. LOS cambios en el régimen electoral. 2. La remoción del alcalde mediante instrumentos de fiscalización del plenario. 3. Los cambios competenciales y de configuración de órganos municipales. 4. La autonomía del alcalde-presidente en el diseño y designación del «entorno ejecutivo» del gobierno municipal. 5. La modulación temporal de las reformas electorales. VI. CONCLUSIONES. BIBLIOGRAFÍA
\end{abstract}

\title{
I. INTRODUCCIÓN
}

El presidente del Gobierno español, Mariano Rajoy, inauguró el verano político de 2014 declarando su voluntad de acometer las reformas necesarias para asegurar que el alcalde o alcaldesa de un municipio sea en todo caso la persona candidata por la lista más votada'. Añadió, por lo demás, su determinación de hacer lo necesario para garantizar la plena efectividad de la medida en los comicios locales de mayo de 2015, si bien, no se han conocido ulteriores precisiones, con la excepción de alguna información relativa a la disposición del Ejecutivo a integrar en dicha propuesta una segunda vuelta electoral, de modo que el modelo definitivo consistiese en atribuir la mayoría absoluta de los concejales a la lista que sobrepase el $40 \%$ de los sufragios en caso de que ninguna candidatura obtuviese la mayoría suficiente de votos².

En defensa de la propuesta se lanzaron diversos argumentos que achacan al vigente sistema de elección indirecta del alcalde a cargo de los concejales, entre otros defectos, el haber propiciado «pactos contra natura, que han sostenido precarios gobiernos municipales formados por coaliciones heterogéneas, con alcaldes procedentes de formaciones políticas minoritarias - $\mathrm{y}$, por tanto, escasamente representativas-, además de facilitar el transfuguismo más corrupto» (DE CARRERAS, 2014)3. De ahí que otro frente de críticas a la propuesta del Gobierno se fundó en la presunción de que el modelo no tenía como prioridad la elección directa de los alcaldes mediante el voto de los ciudadanos, sino más bien la de permitir configurar mayorías absolutas en los consejos plenarios de los municipios, prescindiendo de coaliciones y pactos post-electorales. De donde se derivaría la consiguiente distorsión de la proporcionalidad entre la representación de los grupos municipales y los votos populares, mediante una prima de representación para el grupo mayoritario4.

En efecto, si atendemos a algunos datos del actual contexto político, parece más claro todavía que la propuesta perseguiría consolidar los actuales mapas electorales locales. La mayoría de encuestas vaticinan, por distintas razones, significativas y quizás irreversibles pérdidas a las dos grandes formaciones del sistema de partidos español en algunos de sus feudos históricos, si bien con ganancias globales asimétricas. ${ }^{5}$ Una causa destacada de esos problemas es la fragmentación del voto de los tradicionales espacios de la derecha y la izquierda, provocada por la emergencia de nuevas marcas electorales, constatada en los recientes comicios al Parlamento Europeo $(\text { mayo 2014) })^{6}$.

1 Curiosamente, el criterio de que la alcaldía fuese ocupada por la persona que encabezase la lista más votada formó parte de la agenda política expuesta en el primer debate de investidura de Felipe González (Vid. Diario de Sesiones del Congreso de los Diputados (DSCD), II Legislatura, núm. 4, 1.12.1982, pp. 58-59).

2 «El PP defenderá la elección directa de alcaldes en todos los Ayuntamientos», El País, 23.07.2014. Disponible on-line: http://politica. elpais.com/politica/2014/07/23/actualidad/1406141152 626901.html [Consultado el 18.09.2014].

3 El autor, aunque valora positivamente el fondo de la reforma, la rechaza por razones de oportunidad.

4 La supuesta preeminencia de ese objetivo, juzgado como partidista, ha condicionado el debate político, y buena parte del académico, hasta el punto de que se ha llegado a afirmar que «lo que está aquí en juego no es ni la estabilidad, ni la seguridad, ni la certidumbre, ni por supuesto la regeneración democrática sino mantener a ultranza un sistema partitocrático fundamentado en un bipartidismo intratable y en unos partidos verticales con un poder omnímodo. Ni más ni menos» (RIDAO, 2014a).

5 El barómetro del Centro de Investigaciones Sociológicas (CIS) correspondiente a octubre de 2014 situó a Podemos como primer partido en intención de voto directa en unes elecciones generales con el 17,6\%, frente a un 14,3\% del PSOE y un 11,7\% del PP, que caía del primer al tercer puesto desde julio. Puede consultarse en: http://epoo.epimg.net/descargables/2014/11/05/f65f19988a09564864ddb9414be2f785.pdf [consulta: 25 de enero de 2015].

6 De acuerdo con una serie estadística de encuestas recientes, las transformaciones, de calado, que vive el mapa electoral español son directamente imputables al proceso de deslegitimación social del modelo político de democracia representativa y el sistema de partidos diseñados durante el proceso constituyente. De forma sintética, estos cambios, en el ámbito estatal, se concretan en una significativa deserción de los votantes de los grandes partidos de gobierno estatales, y el ascenso tanto de fuerzas menores tradicionales (IU), como de otras relativamente nuevas (UPyD o Ciudadanos) y, muy especialmente, la potente emergencia del fenómeno Podemos. La demoscopia apunta 
Con todo, fue la pretensión de tener a punto la reforma electoral para aplicarla en las inminentes elecciones municipales, la que centró el núcleo argumentativo de la oposición expresada por distintos partidos políticos, eliminando cualquier posibilidad de apoyo externo al grupo parlamentario que apoya al gobierno, aunque, como es bien sabido que su posición en las Cortes le permitiría aprobarla en solitario.

No obstante lo dicho, lo cierto es que, argumentos de oportunidad al margen, existe una línea de reflexión sobre determinadas carencias de la gobernanza municipal en España, impulsada por dos preocupaciones distintas pero conectadas entre sí: la eficacia de los gobiernos locales y la calidad democrática de estos entes. En cuanto a la primera preocupación, la tendencia que ha guiado buena parte de las últimas reformas institucionales en el régimen local ha sido la de configurar poderes ejecutivos locales fuertes dirigidos y fiscalizados por órganos colegiados de electos inspirados, funcionalmente, en las cámaras parlamentarias?. Por su parte, en la segunda de las materias, se persigue mejorar la adecuación entre las preferencias del electorado, expresadas mediante el voto a las diversas candidaturas y, especialmente, a las personas que las encabezan, con la conformación posterior de las instituciones locales.

Así, pues, el presente trabajo se acoge a la oportunidad que proporciona el debate sobre la reforma anunciada por el ejecutivo central para exponer, principalmente, las razones que podrían aconsejar optar por un modelo de verdadera elección directa de los alcaldes mediante el voto de los ciudadanos y, por tanto, de configuración presidencialista del gobierno municipal, como alternativa al modelo propuesto de prima de representación. Para ello, a continuación se exponen los rasgos definitorios del sistema electoral vigente en el ámbito municipal, las características básicas de un modelo como el propuesto por el Gobierno, sus referentes en el marco del derecho comparado y sus precedentes en otras iniciativas legislativas en España y algunas dudas sobre su incardinación constitucional. Seguidamente, se expone la arquitectura institucional de los gobiernos municipales, derivada del actual régimen local, y sus puntos de contacto con el sistema electoral correspondiente. A continuación, se analizan las principales razones que, a nuestro juicio, justificarían un gobierno local presidencialista y los elementos básicos de una propuesta en este sentido. La siguiente sección detalla, pormenorizadamente, las principales modificaciones legales que comportaría este modelo, tanto en el ámbito electoral como en el de ordenación competencial entre las diversas figuras institucionales de los entes locales. Cierran el trabajo unas someras conclusiones.

\section{EL SISTEMA DE ELECCIÓN DE ALCALDES EN ESPAÑA: CONFIGURACIÓN ACTUAL Y REVISIÓN DE LAS PROPUESTAS PARA SU REFORMA}

La configuración actual del régimen electoral de las instituciones locales es tributaria, en gran parte, del diseño realizado por la transitoria Ley 39/1978, de 17 de julio, de elecciones locales, destinada a regir las elecciones locales a celebrar «dentro del plazo de treinta días, a partir de la promulgación de la Constitución» (disposición transitoria séptima), que a su vez tuvo como antecedente privilegiado la Ley municipal de 1935, la cual no pudo llegar a aplicarse en su día.

Aunque la Constitución contempla la doble posibilidad de que la elección de los alcaldes sea realizada «por los concejales o por los vecinos» (art. 140 CE), es sabido que la Ley Orgánica 5/1985, de 19 de junio, del Régimen Electoral General (LOREG) estableció (art. 196) un sistema mixto ${ }^{8}$, que en primera instancia atribuye la alcaldía a la persona que encabece la lista que reciba los apoyos de la mayoría absoluta de los concejales del plenario y, si esta circunstancia no se produce, asigna la alcaldía a la persona que encabece la lista que haya obtenido un mayor número de votos populares9.

En definitiva, la LOREG dispone, también para el nivel local, un sistema en el que prevalece la designación del cabeza de gobierno por parte de la cámara de electos, sin duda por analogía con el método que la Carta

a una confirmación, e incluso el avance, de esta tendencia en los próximos comicios, en todos los niveles.

7 Con la excepción de la Ley 27/2013, de 27 de diciembre, de racionalización y sostenibilidad de la Administración Local, que abocó sus contenidos, principalmente, a la contención del gasto local mediante una delimitación restrictiva de las competencias locales y la elaboración de criterios comunes, entre otras cosas, para la retribución de los cargos electos y personal eventual.

8 En este artículo nos referiremos exclusivamente al régimen establecido para los municipios de más de 250 habitantes y que no se organizan en sistema de concejo abierto (artículos 179.1, 180 y 196, párrafos primero a cuarto, de la LOREG), dejando, pues, al margen los regímenes específicos como el que se aplica a municipios con una población comprendida entre 100 y 250 habitantes (artículos 184 y 196 , párrafo quinto, de la citada ley), el sistema de concejo abierto (artículo 179.2 de la LOREG) y el de las entidades locales de ámbito inframunicipal y la elección de alcaldes pedáneos (artículo 199 de la LOREG y legislación autonómica).

9 Como señalan algunos autores, este procedimiento, sin embargo, no excluye la existencia de pactos que propicien la abstención de determinados grupos para que, en presencia de candidaturas alternativas en la primera votación, no prospere ninguna diferente de la más votada, hasta el punto de considerarlas coaliciones pasivas o de «no-pacto». La elección mediante la lista más votada no ocupa una posición residual en el sistema español: entre 1979 y 1999, el 26,3\% de las alcaldías de capital de provincia fueron elegidas mediante este sistema, frente al 31,7\% que lo fueron mediante un sistema de coalición entre partidos. Vid. MÁRQUEZ CRUZ, GUILLERMO (2003: p. 173). 
Magna prescribe para la elección del presidente del gobierno del Estado (art. 99 CE) y que es el presente también en todos los gobiernos autonómicos (art. 152.1 CE). En el régimen electoral local, sin embargo, es destacable la exigencia, tanto para la elección por los concejales, como a partir del recuento de sufragios, de que la persona candidata a la alcaldía sea siempre la que encabeza una lista. Este requisito, por ejemplo, no se establece para los candidatos a la presidencia del Gobierno, para los cuales, como se sabe, ni tan sólo es imprescindible la condición de diputado. La LOREG atribuye así, mediante esta opción legislativa, una suerte de «prima de representatividad» para las personas que concurren a una elección local en calidad de cabeza de lista, circunstancia que ha sido subrayada por la jurisprudencia constitucional [Vid. Sentencia del Tribunal Constitucional (STC) 31/1993].

En este contexto, la propuesta del Gobierno, como hemos explicado, y con todas las cautelas que se derivan de su falta de concreción, consiste en asignar a la lista ganadora de unos comicios locales, si no consigue la mayoría absoluta pero supera un determinado umbral de porcentaje de votos (en su caso, en segunda vuelta), la mayoría absoluta de los concejales en juego y repartir el resto en proporción al número de votos populares de cada una de las otras candidaturas. En definitiva, se trataría de establecer para las entidades locales un régimen electoral de «bonus proporcionalizado», un sistema utilizado hoy en las elecciones locales en Francia, Italia ${ }^{10}$ o Grecia, cada país con sus especificidades, y que no resulta desconocido, tampoco, para las Cortes Generales.

Conviene recordar aquí que, si bien los elementos troncales del régimen electoral diseñado en 1985, que consolidaba en lo fundamental lo establecido con carácter transitorio para los comicios previos al orden constitucional" ${ }^{11}$, han gozado de una notable intangibilidad, lo cual no ha venido determinado por la ausencia de iniciativas de reforma, antes al contrario por la incapacidad de los diversos proyectos para concitar simultáneamente el acuerdo de los dos grandes partidos estatales en la conveniencia de modificar el statu quo. Con todo, también cabe asumir la interpretación de que la pertinaz resistencia al cambio de la configuración esencial del sistema electoral español se debe, principalmente, a que «los resultados en su aplicación a las primeras elecciones generales de 1977 fueron considerados idóneos para la transición democrática» ${ }^{12}$. Trasladado al ámbito local, la continuidad que obtuvo el modelo electoral de 1978 puede atribuirse al éxito que obtuvo en el objetivo de «consagrar a los partidos políticos como protagonistas principales del proceso político local, estableciendo un sistema electoral en todo paralelo al vigente para las elecciones generales» (BOTELLA, 1992: p. 150). En cualquier caso, como recuerda BoIx (1999: pp.609-610), en el contexto de las democracias internacionales cuando los sistemas electorales y de partidos se consolidan tienden a estabilizarse y «congelarse», por lo que, con la excepción del establecimiento de regímenes democráticos en estados que no lo eran, los cambios abruptos en la legislación electoral han sido raros en las últimas ocho décadas ${ }^{13}$.

En relación específicamente a las entidades locales, cabe citar la «Proposición de Ley Orgánica de modificación de la Ley Orgánica 5/1985, de 19 de junio, del Régimen Electoral General», presentada por el Grupo Socialista del Congreso en la VI Legislatura ${ }^{14}$, y la sección correspondiente del Informe del Consejo de Estado sobre las propuestas de modificación del régimen electoral General (2009), elaborado a petición de una subcomisión ad hoc creada en el seno de la Comisión Constitucional del Congreso en septiembre de $2008^{15}$, que concluyó sus trabajos en junio de 2010, dejando invariados los elementos medulares del sistema electoral, excepto algún tema procedimental menor (SANTOLAYA, 2009: pp. 223-224).

En síntesis, la Proposición de Ley del Grupo Socialista del Congreso planteó un sistema electoral que combinaba, en una votación de doble papeleta, la elección directa de los alcaldes con un sistema de bonus proporcionalizado, para la elección de concejales. En el caso de los alcaldes se contemplaba la posibilidad de que las personas candidatas pudieran concurrir en representación de una o más de las listas de candidatos a concejales, sin que para ello fuera necesario que encabezara alguna de ellas. También se preveía una doble vuelta, en caso de que ninguna de las candidaturas a la alcaldía obtuviese, en primera instancia, la mayoría absoluta de los votos, restringida a las candidaturas que hubiesen sobrepasado el $15 \%$ de los votos válidos. Para garantizar

10 Desde la Ley núm. 81, de 25 de marzo de 1993, este sistema afecta a las quince regiones de estatuto ordinario, mientras que en cuatro regiones de estatuto especial (Friuli-Venezia Giulia, Cerdeña, Trentino-Alto Adige/Sur de Tirol y el Valle de Aosta) sigue vigente el sistema proporcional y la elección del alcalde por parte del consejo municipal. Sicilia, mediante la Ley regional núm. 7, de 13 de agosto de 1992, había implantado un sistema acusadamente presidencialista.

11 Esto es, el Real Decreto-ley 20/1977 y la precitada Ley 39/1978, de 17 de julio, de elecciones locales.

12 Vid. la aportación de SANTOLAYA MACHETti, PABlo en ARIÑo ORTIZ, GASPAR ET AL. (2008: p. 39).

13 MONTERO y RIERA (2009: pp. 242-244) proporcionan una exhaustiva relación de reformas electorales en países democráticos entre 1946-2005. Excluyendo los establecimientos de sistemas electorales propiamente dichos, por ejemplo en los países provenientes del antiguo bloque soviético, y los cambios no fundamentales, en general subsiste la impresión de estabilidad apuntada por Boıx.

14 Boletín Oficial de las Cortes Generales (BOCG), Congreso de los Diputados. VI Legislatura, núm. 256-1, 7.12.1998.

15 Vid. DSCD. Comisiones, IX Legislatura, 68, 5.09.2008; BOCG, Congreso de los Diputados, IX Legislatura, núm. 64, 15.09.2008. 
la gobernabilidad de los municipios, se proponía asignar el bonus en la elección de concejales a la candidatura o grupo de candidaturas que hubiesen dado apoyo a la persona ganadora de la candidatura a la alcaldía, en concreto el $55 \%$ del total de electos del plenario municipal.

Por su parte, el Consejo de Estado, en su precitado informe, sin entrar en la configuración detallada de un modelo específico, aboga con claridad por un modelo que combine representatividad de los alcaldes electos y gobernabilidad de los entes locales (pp. 265-266), sugiriendo, en fin, una combinación de elección directa de los alcaldes y de bonus para la atribución de las actas de concejal. De esta manera, según su parecer consultivo se perfilaría un modelo que denomina «de alcalde presidencialista» y que tendría como puntos centrales la «[e] lección directa frente a la indirecta por los concejales; tendencia hacia elementos de un sistema mayoritario (o de candidato) frente a otro proporcional; mayor gobernabilidad, claridad de acuerdos y evitación del transfuguismo frente a la formación artificiosa de mayorías» (p. 267).

Ciertamente, algún sector doctrinal ha planteado dudas sobre la constitucionalidad de un sistema que, eventualmente, pueda incorporar distorsiones de una magnitud tan significativa en la proporcionalidad respecto a la voluntad popular ${ }^{16}$, sobre todo teniendo en cuenta que ésta se añadiría a las que se derivan del sistema vigente, esto es, la determinación de un número de representantes en función de la población (art. 179.1 LOREG), la exclusión de la asignación de representantes de las candidaturas que no obtengan un mínimo del $5 \%$ de los votos válidos (art. 180 LOREG) y el propio método de asignación mediante la ley D’Hondt (Art. 163.1 LOREG).

No obstante, este argumento parece de corto recorrido. Efectivamente, la Carta Magna estableció el principio de proporcionalidad, no como una cualidad inherente al sistema electoral, sino como un referente para la designación de representantes en el Congreso de los Diputados (art. 68.1 CE), la representación autonómica (art. 152.1 CE) o los senadores de designación autonómica (art. 69.5 CE). Además, atribuyó al desarrollo legislativo, en este caso mediante ley orgánica (art. $81 \mathrm{CE}$ ), la responsabilidad de definir el método concreto de translación de los votos obtenidos por cada candidatura en número de representantes asignados. De esta manera, la jurisprudencia constitucional ha venido interpretando que

«[L]a proporcionalidad es, más bien, una orientación o criterio tendencial, porque siempre, mediante su puesta en práctica, quedará modulada o corregida por múltiples factores del sistema electoral, hasta el punto que puede afirmarse que cualquier concreción o desarrollo normativo del criterio, para hacer viable su aplicación, implica necesariamente un recorte a esa «pureza» de la proporcionalidad abstractamente considerada» (STC 75/1985, FJ 5).

Por otro lado, no se olvide que el TC ha señalado que «cuando se habla del escrutinio proporcional, lo que se está manifestando es una voluntad de procurar, en esencia, una cierta adecuación entre votos recibidos y número de escaños, atribuyendo a cada partido o grupo de opinión un número de mandatos en relación con su fuerza numérica, una representación sensiblemente ajustada a su importancia real» (STC 76/1989 FJ 4, 40/1981 FJ 2 y 75/1985 FJ 5), de manera que

«[E]n tanto el legislador [...] se funde en fines u objetivos legítimos y no cause discriminaciones entre las opciones en presencia, no cabrá aceptar el reproche de inconstitucionalidad de sus normas o de sus aplicaciones en determinados casos, por no seguir unos criterios estrictamente proporcionales» (STC 193/1989, FJ 4).

Siendo, además, que la gobernabilidad es un criterio que el Alto Tribunal considera relevante en la evaluación del sistema electoral, cuando se debe equilibrar «el riesgo que, en relación a [la gobernabilidad], supone la atomización de la representación política, por lo que no parece, por lo tanto, ilegítimo que el ordenamiento electoral intente conjugar el valor supremo que, según el art. 1.1 de la C.E., representa el pluralismo —y su expresión, en este caso, en el criterio de la proporcionalidad - con la pretensión de efectividad en la organización y actuación de los poderes públicos» (STC 75/1985, FJ 5).

La preocupación por la gobernabilidad de las cámaras de electos resultantes de las votaciones populares, a veces casi por encima de la representatividad democrática, es un factor común a la reciente propuesta del Gobierno, al modelo apuntado por el Consejo de Estado y a la aludida proposición socialista de la VI Legislatura. Es más, entronca con un cierto principio de «exigencia racionalizadora» que la doctrina del TC reputa en determinados preceptos constitucionales (cfr. art. 99.5 CE) y que le lleva afirmar que,

16 Vid. García FernándeZ, JAVIER (2014). 
«[J]unto al principio de legitimidad democrática de acuerdo con el cual todos los poderes emanan del pueblo —art. 1.2 de la CE—y la forma parlamentaria de gobierno, nuestra Constitución se inspira en un principio de racionalización de esta forma que, entre otros objetivos, trata de impedir las crisis gubernamentales prolongadas» (STC 16/1984, FJ 6) 1 .

Con todo, aun reconociendo que la «exigencia racionalizadora» es un elemento a tener destacadamente en cuenta, en su acepción de garantía de gobernabilidad, no estimamos que deba ocupar una posición del mismo rango que la legitimidad democrática, como luego desarrollaremos a la hora de trazar la arquitectura de un sistema electoral, puesto que la representatividad de la composición de las cámaras de electos debe ser una expresión patente, con todas las modulaciones que incorpore el sistema electoral, del pluralismo de la voluntad popular (art. 1.1 CE).

\section{LA CONFIGURACIÓN INSTITUCIONAL DEL GOBIERNO MUNICIPAL Y SU INTERRELACIÓN CON EL RÉGIMEN ELECTORAL}

Las instituciones de gobierno local que definió la Ley 7/1985, de 2 de abril, reguladora de las Bases del Régimen Local (LRBRL) ${ }^{18}$ diferenciaban, claramente, un poder ejecutivo con una importante autonomía, ejercido por el alcalde con la asistencia de un «entorno ejecutivo» ${ }^{19}$, orientado y fiscalizado por un órgano colegiado de electos (el plenario), articulados sobre una base de inspiración parlamentaria. MÁRQUEZ CRUZ (1999: p. 312) señala que, en sus elementos esenciales, este modelo evolucionó los instrumentos jurídico-políticos de normalización del nivel local que se establecieron en la dictadura de Primo de Rivera (Estatuto Municipal de 1924), se constitucionalizaron en la II República (1935) y se mantuvieron, en gran parte, durante el franquismo (1955) y el tardofranquismo (1975)20.

Con el tiempo, la aplicación del modelo de 1985 puso de manifiesto determinadas ineficacias derivadas de la superposición de las funciones de control de la gestión del consejo plenario con las competencias de gestión propiamente consideradas, cuya corrección constituyó uno de los ejes de la reforma de 1999 (Ley 11/1999, de 21 de abril), a consecuencia de lo que se vino a denominar como «Pacto Local», y posteriormente fue plasmado en la Ley 57/2003, de 16 de diciembre, de medidas para la modernización del gobierno local. El criterio con el que se resolvieron, en ambos casos, las disfunciones en la gobernabilidad local fue el de concentrar las competencias de carácter ejecutivo en la alcaldía y ampliar los rasgos de «cámara parlamentaria» del consejo plenario, principalmente en materia fiscalizadora de la esfera ejecutiva.

Así, por ejemplo, la reforma de 1999 amplió de forma sustancial las materias competenciales atribuidas a la alcaldía, especialmente en los límites de ejecución del presupuesto de gastos, la gestión del personal, la autorización de contratos y concesiones ${ }^{21}$, la aprobación de instrumentos de planeamiento urbanístico o el otorgamiento de licencias. Por su parte, el plenario retuvo las competencias en materia de planificación urbanística general y aprobación final de los instrumentos de planeamiento derivados, la aprobación del presupuesto anual y la relación de puestos de trabajo, así como la autorización de las operaciones económicas y de contratación por encima de los límites monetarios otorgados a la alcaldía.

La reforma de 1999 se acompañó de una reforma del régimen electoral (Ley orgánica 8/1999, de 21 de abril) que adaptó al ámbito local la cuestión de confianza (art. 197bis LOREG), como ultima ratio para intentar superar las situaciones de bloqueo de la gobernabilidad en el proceso de adopción de decisiones en materias de especial trascendencia para gobierno municipa ${ }^{22}$. Así, se erigió junto con la moción de censura (art. 197 LOREG) una dupla de instrumentos fiscalizadores de la actividad del ejecutivo municipal de indudable potencial, ya que su votación en el plenario podía tener como resultado, en ambos casos, la remoción del titular de la alcaldía y de todo su

17 El concepto «parlamentarismo racionalizado» fue acuñado y elaborado originalmente por MIRKINE-GUETZÉVITCH en 1930, en su obra Les constitutions de l'Europe Nouvelle, París: Librairie Delagrave.

18 El régimen municipal español alberga una pluralidad de sistemas de gobierno, pero en este trabajo nos referiremos principalmente al régimen general o común (arts. 19 a 24 LRBRL), aunque también abordaremos determinados aspectos del régimen singular de municipios de gran población (Título X LRBRL). Quedarían, pues, excluidos de este análisis los regímenes de concejo abierto (art. 29 LRBRL) y los especiales de definición autonómica (art. 30 LRBRL).

19 Acertada expresión utilizada por el profesor MÁRQUEZ CRUZ en diversas de sus obras (cfr. 2003: p. 167) y que comprende la Junta de Gobierno Local (inicialmente denominada Comisión de Gobierno), los tenientes de alcalde y los concejales delegados (arts. 20 y 23 LRBRL).

20 CAAMAÑo (2004, p.28-30) señala, en este mismo sentido, que la opción por una «filosofía modernizadora pero continuista» condicionó, entre otras cosas, la fórmula para la elección de los regidores municipales.

21 Estas atribuciones fueron, sin embargo, redefinidas por la Ley 30/2007, de 30 de octubre, de Contratos del Sector Público.

22 En concreto, la ley limita su uso a los supuestos de la aprobación de los presupuestos de la corporación, del reglamento orgánico, de las ordenanzas fiscales y la aprobación que ponga fin a la tramitación municipal de los instrumentos de planeamiento general de ámbito municipal. 
«entorno ejecutivo». La indudable inspiración parlamentaria de dichos instrumentos no ha estado exenta de controversia doctrinal. COSCULLUELA MONTANER (1988: p. 724) calificó la introducción de la moción de censura en el ámbito local de «indiscriminada aplicación de técnicas parlamentarias a las relaciones entre órganos de las Corporaciones locales»; por su parte, MÁRQUEz CRUZ (1994: p. 256) ha señalado lo extraño de que la exigencia de responsabilidades políticas mediante ese tipo de figuras se produzca en una «dimensión funcional y no estrictamente orgánica», ya que tanto el alcalde, como el resto de concejales que forman el «entorno ejecutivo», se integran en el mismo órgano que la realiza, y por la misma razón que el resto de ediles: el hecho de haber sido elegidos democráticamente. En este sentido, también el profesor SANTOLAYA ha constatado

«Una patente inadecuación entre el modelo funcional y competencial de los Ayuntamientos como ejecutores de las políticas del bienestar, que implica una notable estabilidad de sus gobiernos y de su sistema electoral «parlamentarizado» y altamente proporcional, basado en la elección del Alcalde por los concejales, en los que éstos conservan la plenitud de derechos inherentes a su cargo, incluido el de cambiar el gobierno del municipio mediante la moción de censura»²3.

En este contexto, cabe recordar que cuando el TC declaró la inconstitucionalidad de la llamada «revocación del partido» ${ }^{24}$, combinada con la moción de censura local habilitada por la LOREG (1985), a partir de apreciar «que los representantes elegidos lo son de los ciudadanos y no de los partidos, y que la permanencia en el cargo no puede depender de la voluntad de los partidos sino de la expresada por los electores a través del sufragio expresado en elecciones periódicas» (STC 5/1983, FJ 4) ${ }^{25}$, de facto se abrió la puerta al fenómeno del «transfuguismo». Éste, rechazado de forma unánime y reiterada por la generalidad de partidos, por lo menos de aquellos con representación en las Cortes Generales, fue objeto de un acuerdo estatal formal para evitar su utilización en los gobiernos locales en 1998 («Pacto Antitransfuguismo»), fue renovado en 2000 y 2006, si bien es ampliamente constatable que no se ha conseguido erradicar completamente la tolerancia, más o menos disimulada, con su práctica, como muestran las periódicas denuncias cruzadas ante la comisión de seguimiento del mencionado pacto.

Por su parte, la reforma de 2003 consolidó el reparto de atribuciones del «Pacto Local» y estableció un régimen diferenciado de gobierno local para los municipios de gran población. Este novedoso régimen reafirmó una visión compartida, por lo menos por las fuerzas parlamentarias mayoritarias, del horizonte institucional al que debe dirigirse el régimen local, esto es, un poder ejecutivo reforzado, capaz de «[a]tender a la necesidad de un liderazgo claro y diáfano ante la sociedad» y una asamblea de electos deliberativa y fiscalizadora, de base parlamentaria, donde realizar «un debate político abierto y creativo sobre las principales políticas de la ciudad, así como profundizar en el control de la acción de un ejecutivo reforzado» (véase en ese sentido el apartado I de la Exposición de Motivos de la Ley 57/2003). Asílas cosas, paradójicamente, la figura del alcalde, aunque vio reforzados sus caracteres presidencialistas, adquirió un perfil eminentemente representativo y menos vinculado a la gestión ejecutiva, cuyo peso central se trasladó a la Junta de Gobierno Local ${ }^{26}$, concediendo mayor relevancia a lo que antes hemos descrito como «entorno ejecutivo» de la alcaldía. Dicho órgano no sólo se define competencialmente de una forma detallada en la ley (art. 127 LRBRL), sino que su configuración institucional adquiere una precisa nitidez (art. 126 LRBRL), si bien, como luego desarrollaremos, algunos aspectos de la misma han sido objeto de reproche constitucional. Este reproche, a nuestro entender, se derivaría de una incorrecta configuración del «entorno ejecutivo", que la ley pretende hacer efectiva mediante su configuración híbrida, a caballo entre la funcionalidad ejecutiva y la dirección política ${ }^{27}$, sin tener sin embargo en cuenta la rigidez que introducía la inequívoca asignación constitucional del «gobierno y administración» municipales al cuerpo de electos (art. 140 CE).

Por lo que respecta al plenario, la reforma de 2003 profundizó como hemos dicho los atributos parlamentarios de su configuración. En especial, el régimen para las grandes ciudades contemplaba la posibilidad de que su

23 Vid. su aportación en ARIÑo ORTIZ, GASPAR ET AL. (2008: p. 56).

24 Esta expresión hacía referencia a lo establecido en el art. 11.7 de la mencionada Ley de Elecciones Locales de 1978: «Tratándose de listas que representen a partidos políticos, federaciones o coaliciones de partidos, si alguno de los candidatos electos dejare de pertenecer al partido que le presentó, cesará en su cargo y la vacante será atribuida en la forma establecida en el número anterior. El que así accediere ocupará el puesto por el tiempo que restare de mandato».

25 La STC 5/1983 (FJ 4) prosigue estimando que, a partir de este principio, «debe afirmarse que el art. 11.7 de la Ley de Elecciones Locales, en cuanto otorga a los partidos políticos la posibilidad de crear por su voluntad —mediante la expulsión- el presupuesto de hecho que da lugar al cese en el cargo público va contra la Constitución y, en concreto, contra el derecho a permanecer en el cargo público de su art. 23.2, al prever una causa de extinción o cese contraria a un derecho fundamental susceptible de amparo como es el regulado en el art. 23.1 de la misma».

26 Denominación que recibe, desde la reforma de 2003, la Comisión de Gobierno de la Ley de 1985.

27 La misma exposición de motivos de la Ley $57 / 2003$ menciona dicha naturaleza dual al afirmar que «se viene a perfilar una Junta de Gobierno Local "fuerte", que sustituye a la Comisión de Gobierno, dotada de amplias funciones de naturaleza ejecutiva, y que se constituye como un órgano colegiado esencial de colaboración en la dirección política del Ayuntamiento» [las cursivas son nuestras]. 
presidencia fuera delegada por el alcalde en algún otro concejal (art. 122.2 LRBRL). También son de destacar otros elementos de raíz claramente parlamentaria, como el funcionamiento en comisiones (art. 122.4 LRBRL), la aprobación de los reglamentos de naturaleza orgánica (art. 123.1 c LRBRL), incluido el propio del plenario (art. 122.3 LRBEL). Conviene no perder de vista que, a pesar del criterio general de deslindar los ámbitos ejecutivos y deliberativo/fiscalizador, el plenario tiene notables asignaciones de índole ejecutiva como, por ejemplo, determinar las grandes áreas de gobierno (art. 123.1 c LRBRL).

En suma, como bien señala el profesor DELGADO-IRIBARREN,

«[A]bordar la reforma del sistema electoral sin tener en cuenta el perfil global de la institución sólo puede conducirnos a situaciones de desequilibrio e inestabilidad en la Corporación municipal. La forma de elección debe ser congruente con el resto del estatuto del cargo representativo (y singularmente con los procedimientos de remoción del cargo), así como de sus funciones y competencias» ${ }^{28}$.

\section{LA CONVENIENCIA DE UN RÉGIMEN PRESIDENCIALISTA EN EL GOBIERNO MUNICIPAL}

Es evidente que la crisis de legitimidad que afecta actualmente al conjunto de instituciones que conforman la arquitectura de la democracia española, especialmente al sistema de partidos, tiene un carácter poliédrico, por lo que difícilmente hallará una solución global en la reforma del sistema electoral, por profunda que ésta sea. Sin embargo, no es menos cierto que existen notables y suficientes elementos en la actual coyuntura social y política que impelen a la adopción de un cambio en el sistema electoral, con un alcance más o menos radical (RIDAO, 2014: pp. 21-22). Y es en ese sentido que parece que el nivel local podría ser el que menos dificultades procedimentales planteara, ya que cuenta con menor rigidez constitucional que las cámaras estatales y no cuenta, tampoco, con legislación autonómica específica. Por otro lado, aunque este nivel de gobierno cuenta con una significativa presencia de los partidos políticos dominantes en la esfera tanto estatal como autonómica, es indudable que ha albergado sin aparente dificultad a otras formaciones políticas menores, algunas de ellas específicas del ámbito local.

Efectivamente, en el mundo local han abundado las llamadas candidaturas «extrañas» (UBASART-GONZÁLEZ, 2012: pp. 137-138) ${ }^{29}$ que han permitido articular diferentes movimientos sociales y políticos, de alcance estrictamente local, entorno a una propuesta electoral formulada, habitualmente, mediante mecanismos muy directos de interacción con el electorado. A estos efectos, UBASART-GONZÁLEZ ha constatado (2012: pp. 146-151) que este fenómeno, después de unos años de estabilización e incluso declive, volvió con fuerza a principios del siglo XXI, instalándose en municipios cada vez con mayor población y desplazando, en la mayoría de casos, el núcleo del eminentemente "gerencial» a otro de contenido marcadamente «político». Se ha observado así lo que podría describirse como un tránsito gradual y nítido de las tradicionales reivindicaciones vinculadas usualmente a planificaciones urbanísticas o al goce de determinados equipamientos hacia un discurso articulado sobre el «modelo de ciudad» o la forma de gobernar el consistorio, a partir de una prescripción amplia de fórmulas de democracia directa.

Por otro lado, cómo hemos ido apuntando en el apartado precedente, hay una extendida opinión, por lo menos en el ámbito académico, en el sentido de que,

«[L]a insistencia recalcitrante en copiar el modelo parlamentario para su aplicación al ámbito local sigue siendo el hándicap o tope intelectual del que se parte cuando quizás habría que pensar más bien en la huida del Derecho Parlamentario para la concebir las Corporaciones locales desde una perspectiva gerencial, con un Alcalde electo por una mayoría cualificada, en una o dos vueltas, con capacidad para el nombramiento del equipo gestor o directivo de los servicios municipales»30.

Claro está que los sistemas electorales son instituciones redistributivas, es decir, en las cuales la ganancia de un grupo concreto se realiza, en un modelo de suma cero, a costa de los otros grupos actores ${ }^{31}$; esta condición es relevante, porque hace inaplicables los modelos explicativos del establecimiento y reforma de los sistemas

28 Vid. su valiosa aportación en ARIÑo ORTIZ, GASPAR ET AL. (2008: p. 50).

29 El concepto, tal y como lo define la autora mencionada, hace referencia a «todas aquellas candidaturas localistas o municipalistas distintas a las presentadas por los partidos políticos parlamentarios y extraparlamentarios de alcance supra-local».

30 Vid. la aportación de ARNALDO ALCUBILLA, ENRIQUE en ARIÑo ORTIZ, GASPAR ET AL. (2008: pp. 49-50)

31 En contraposición a las llamadas instituciones de eficiencia, en las cuales cabe una modificación que mejore, simultáneamente, la situación de los actores respecto al status quo. 
electorales a partir de las teorías cooperativas o de eficiencia institucional (BENOIT, 2004: p. 366) 32. Sin embargo, las lecturas que no identifican en la formación de los sistemas electorales la concurrencia de otras dinámicas distintas a las basadas en el interés partidista constituyen una aproximación manifiestamente incompleta. Hay suficiente constancia, histórica y comparada, de la entrada en juego de factores relativos al interés general (la representatividad, la gobernabilidad, la pluralidad o la discriminación positiva, etc.) u otros de carácter no instrumental (los precedentes históricos, las prescripciones tecnocráticas, las demandas populares o los factores idiosincráticos) (BENOIT, 2004: pp. 367-373).

Es en este contexto en el que, como ya hemos anticipado en la introducción, nos proponemos formular una propuesta para establecer un sistema netamente presidencialista de la elección de las personas titulares de las alcaldías. A la sazón, los apartados siguientes desarrollan las modificaciones de la norma electoral necesarias para concretarlo, así como los cambios relativos a la ordenación de las competencias del poder ejecutivo local y del plenario de concejales que aportarían congruencia al nuevo modelo de gobierno local.

Con todo, ante todo debemos significar que, si con anterioridad hemos hecho referencia a la existencia de una opinión académica más o menos extendida a favor de una reforma de este tipo, es justo señalar que esa opinión dista de ser unánime. Así, por ejemplo, SÁNCHEZ SÁEZ (2006: p. 187), considera que una modificación presidencialista del gobierno local, valorada por él a partir de un sistema de elección de bonus proporcionalizado, no sólo no forma parte de las prioridades de la reforma local, sino que además no produciría buenos resultados. Para sustentar su opinión, recurre a la experiencia italiana y afirma que un sistema presidencialista no sólo distorsionaría la representación adecuada de la voluntad popular, centraría el debate sobre las personas y no sobre los programas y dejaría sin solución la situación de gobiernos presididos por un Alcalde que ha perdido la confianza de su partido.

Sin menoscabo de este tipo de argumentos, lo cierto es que, en la vertiente doctrinal, existen numerosos elementos que sustentarían una reforma para la configuración presidencial tanto del sistema de elección de las personas que ocupen las alcaldías, es decir con un método de elección directa a partir del voto popular, como de los órganos de gobierno local. No es el menor de ellos el hecho de que la Carta Magna lo contempla, pero también la legislación sectorial ha ido dibujando progresivamente, como ya hemos visto, una figura del jefe del ejecutivo local dotada de unas atribuciones y una autoridad que resultan netamente superiores a las de cualquier otra figura homóloga en cualesquiera de los niveles de Administración, en un régimen que algunos han calificado de semipresidencialista (MÁRQUEZ CRUZ, 2003: pp. 161-162).

Así, el artículo 21.1 de la LRBRL lo designa claramente como «Presidente de la Corporación», a la vez que le asigna casi todas las competencias necesarias para el ejercicio de la gestión ordinaria del ente local. Por su parte, el artículo 23 (arts. 126 y 127 para los municipios de gran población) configura la Junta de Gobierno Local como órgano ejecutivo auxiliar, claramente subordinado a su figura, dado que no sólo designa libremente a sus miembros (art. 23.1 y 126.2 para los municipios de gran población), sino que también recibe el grueso de sus competencias por delegación presidencial (arts. 23.2 b y 23.4 ) 33 .

Adicionalmente, no debe ignorarse que, en tanto que instancia administrativa más próxima a los ciudadanos, a menudo se ha hablado de la importancia de la persona candidata a la alcaldía como factor casi determinante en la valoración de los ciudadanos y, en consecuencia, de los resultados electorales de una lista, de forma mucho más intensa que en ningún otro tipo de contienda electoral (MÁRQUEZ CRUZ, 2003: p. 165). BARBERÁ (2010) y RIERA (2011) han trabajado algunas evidencias empíricas en este sentido.

MÁRQUEZ CRUZ (1994: p. 265) ya había apuntado esta peculiaridad que se traducía, entre otras cosas, en una potencial tensión entre las dinámicas nacionales y locales, así como en la práctica de formas de reclutamiento de candidatos más abiertas que en otros tipos de elecciones; de todo ello, concluía que,

«[L]a debilidad de la vinculación a la formación política por la que resulten elegidas las élites políticas locales - junto a la incidencia de otras variables internas y externas — son elementos que conducen a comportamientos de movilidad política o de transfuguismo en proceso y, por tanto, de inestabilidad política».

32 En este sentido, hay que considerar poco operativos los planteamientos de reforma del sistema electoral, en relación específicamente a la mejora de la proporcionalidad en la representación en el Congreso de los Diputados, que parten de una ampliación del numero global de escaños hasta alcanzar la cifra máxima permitida por la Constitución (400, art. 68.1 CE), como incentivo para un eventual acuerdo estableciendo, así, una transacción entre la naturaleza redistributiva y eficiente [por ejemplo, en diversas aportaciones en ARIÑO ORTIZ, GASPAR ET AL. (2008) o en COMISIÓN DE ESTUDIOS DEL CONSEJO DE ESTADO (2009: pp. 190-192)].

33 En el caso de los municipios de gran población, el art. 127 LRBRL realiza una asignación más detallada de las competencias propias de la Junta de Gobierno. 
Es indudable que también las propias estructuras internas de los partidos políticos han constatado este comportamiento electoral, como se intuye ante la tolerancia que destilan algunas heterodoxas e incluso espurias acusaciones formales de irregularidades por parte de militantes que detentan una alcaldía y que, en otra circunstancia, serían indudablemente objeto de un tratamiento disciplinario mucho más severo. Y también es cierto que esta íntima vinculación entre persona candidata y voto hace que, pese a su incontestable legalidad, las coaliciones de listas separadas que arrebaten la alcaldía a la lista más votada, bien sea inmediatamente después de las elecciones o bien como resultado de una moción de censura, sean interpretadas a menudo como usurpaciones de la voluntad popular.

Recapitulando, pues, nos encontramos con una realidad actual en la que es palmaria la existencia de una adecuada cobertura constitucional para la elección directa de los alcaldes; un régimen local que precisaría unos retoques limitados para acomodar un modelo abiertamente presidencial de gobierno; y un comportamiento electoral de los ciudadanos que otorga un papel destacado, cuando no determinante, a la persona que encabeza la lista a la hora de decidir la asignación del voto. Así las cosas, creemos que una elección directa de los alcaldes incrementaría la calidad democrática del sistema político si concurriesen los siguientes parámetros:

1. Realizar las elección en el ámbito local mediante doble papeleta, una para los concejales del plenario y otra para la alcaldía-presidencia.

2. Habilitar una segunda vuelta restringida para la elección de alcaldes, en el caso de que ninguna de las personas candidatas obtengan la mayoría absoluta en la primera elección. electos.

3. Asignar al plenario una dinámica y unas competencias adecuadas al papel de cámara de representantes

4. Definir un entorno ejecutivo del alcalde-presidente con atribuciones esencialmente gerenciales, a desarrollar esencialmente bajo el control político del plenario y con un margen de discrecionalidad amplio para su configuración funcional y designación por parte de la alcaldía.

5. Suprimir la institución de la moción de censura en el ámbito local.

6. Establecer una modulación temporal, de rango constitucional, de las reformas del régimen electoral, para impedir un uso puramente partidista de las mismas.

\section{ALGUNAS REFLEXIONES ADICIONALES SOBRE LAS REFORMAS LEGISLATIVAS NECESARIAS PARA LA ELECCIÓN DIRECTA DE LOS ALCALDES}

\section{Los cambios en el régimen electoral}

Nuestra propuesta implica, en primer lugar, una modificación sustantiva del régimen de las elecciones municipales (Título III LOREG). La elección directa, mediante el voto popular, de la persona que ocupe la alcaldíapresidencia del municipio obligaría, por razones de representatividad, a estructurar un proceso de decantación de una mayoría, en caso de que en primera votación ninguna de las candidaturas concurrentes obtuviese la mayoría absoluta de los votos emitidos. El sistema más habitual en estos casos es la previsión de una segunda vuelta, con la competencia restringida a las candidaturas que hayan alcanzado un umbral mínimo en primera vuelta, diferida con un margen razonable de tiempo respecto a la primera (usualmente, en torno a 15 días). Un primer punto significativo, pues, los constituye la necesidad de establecer los criterios de acceso a la segunda vuelta. A nuestro parecer, tanto la selección de un determinado número de las candidaturas más votadas en la primera vuelta, como el establecimiento de un umbral de porcentaje de votos podrían ser métodos adecuados para estructurar una segunda vuelta, en la que, en todo caso, debería asegurarse la concurrencia plural de candidaturas y, al mismo tiempo, una mínima representatividad de los competidores finales ${ }^{34}$.

Otro elemento a tener en cuenta es la previsión de alguna fórmula de substitución de la persona titular de la alcaldía-presidencia en caso de vacante forzosa, por razones naturales o por las legalmente establecidas, o bien en el supuesto de dimisión. Como examinaremos más adelante, nuestra propuesta suprime la moción de censura (art. 197 LOREG) pero no la de confianza (art. 197bis LOREG), si bien en caso de cese por esta última se contemplan algunas especialidades sobre la sucesión que expondremos en su momento. La habilitación de un procedimiento específico para que el plenario escoja, de entre sus miembros, la persona que deba substituir

34 En la proposición socialista de 1998 de reforma de la LOREG que hemos expuesto en la sección III, se fijó un porcentaje de corte en el $15 \%$ de los votos válidos, mientras que en el sistema francés se establece el 10\%, aunque hay que recordar que ambos son sistemas de bonus proporcionalizado, en los que también se eligen los representantes del plenario; por su parte en el sistema italiano presidencialista se limita a las dos listas más votadas en primera instancia. 
el alcalde-presidente electo es una posibilidad viable aunque quebraría la lógica de la elección directa. En este sentido parece más coherente configurar para la elección de los alcaldes un «tíquet» electoral compartido con la persona candidata a ocupar la vicepresidencia o primera tenencia de alcaldía ${ }^{35}$, entre cuyas funciones estaría la de substituir la vacante del titular de la alcaldía, lo cual permitiría asegurar la continuidad con la voluntad popular manifestada en la elección del alcalde.

La elección separada, por un lado, del alcalde (con o sin vicepresidente) y de los concejales del plenario, abre adicionalmente algunas posibilidades que cabe escrutar detalladamente. La primera de las cuales es la posibilidad de que las candidaturas a la alcaldía no tengan por qué coincidir con las candidaturas al plenario, esto es, que dos o más formaciones políticas que presenten candidaturas separadas al plenario puedan acordar presentar una candidatura común a la alcaldía, posibilidad que estimamos conveniente recoger y articular en la legislación ${ }^{36}$. Otra cuestión es si las personas candidatas a la alcaldía pueden o no concurrir, simultáneamente, a la elección de los concejales. Es indudable que el alcalde-presidente y, en su caso el vicepresidente-primer teniente de alcalde deben tener ambos la condición de concejal ya que, en caso contrario, tendrían difícil encaje ex art. 140 CE. Sin embargo también parece legítimo que las formaciones políticas que presenten sus líderes como candidatos a la alcaldía puedan preferir, a la vez, que en caso de no resultar electos contribuyan a las tareas de control y orientación política propias del plenario, por lo que dicha posibilidad debería contemplarse expresamente, por ejemplo, previendo la posibilidad de que si uno (o dos) de los concejales electos en una candidatura resultan escogidos para la alcaldía puedan ser substituidos con personas de la misma lista.

Por su parte, la elección de los concejales no requiere de cambios sustanciales respecto a la configuración actual. La circunscripción única para todo el municipio, que debería continuar como criterio ${ }^{37}$, permite restringir las limitaciones de la proporcionalidad a tres: la asignación de representantes a repartir en función de la población (art. 179.1 LOREG), el umbral de acceso al reparto de concejales (art. 180 LOREG) y el método de asignación de representantes (Ley D’Hont, art. 163.1 LOREG). En los dos primeros aspectos citados, más allá de las ocasionales quejas de las candidaturas que, en algún momento, se han visto afectadas, no hallamos fundamento suficiente para su modificación (más allá del hecho de tener en cuenta que uno o dos puestos del plenario serían asignados por la votación a la alcaldía) y, por el contrario, sí convenimos en que existe un criterio de oportunidad política que aconsejaría dejar intactas ambas cuestiones. Por último, aunque es obvio que la «Ley D’Hont» presenta números aspectos criticables, no parece que ninguno de las fórmulas alternativas de asignación proporcional de concejales en función de los votos (por ejemplo, la cuota Hare/Niemeyer o el método Saint-Laguë) altere fundamentalmente los resultados finales en la mayoría de casos (VALLÉs Y BOSCH, 1997), si bien, debemos dejar constancia de que el planteamiento de reforma que efectuamos no resulta incompatible con un eventual cambio en la norma de reparto.

Con todo, no ignoramos que el principal problema de nuestra propuesta se plantea en términos de gobernabilidad. Aunque, como luego veremos, la propuesta contempla una mayor concentración de las competencias ejecutivas en la alcaldía y su entorno, es evidente que existen materias que, aun contando con derivaciones ejecutivas, en nuestra opinión tienen una transcendencia política de tal dimensión que desaconseja sustraerlas a la competencia del plenario, por ejemplo la aprobación del presupuesto o las ordenanzas fiscales. En dichos supuestos, el modelo propuesto aquí no aporta ninguna modificación respecto a la situación actual y ésta es una elección consciente. Creemos que la elección presidencialista de la alcaldía, con la componente mayoritaria que le es inherente, ha de encontrar precisamente una adecuada ponderación democrática en la proporcionalidad derivada de la composición representativa de la asamblea de electos. Por otro lado, la elección dual abre un escenario político inédito en nuestra democracia, en el cual convivirían dos legitimidades distintas, muy diferente al actual, en el cual la alcaldía emana de la misma legitimidad que conforma el plenario. Ello, sin duda, otorgaría un margen de autonomía superior al ejecutivo local para articular mayorías entorno a sus proyectos concretos, a la par que una menor dependencia de la continuidad de esas mayorías.

\section{La remoción del alcalde mediante instrumentos de fiscalización del plenario}

Como ya se ha apuntado, la redefinición presidencialista del gobierno municipal mediante la elección directa por parte de los vecinos de la persona que ha de ocupar la alcaldía, parece a todas luces incoherente con la

35 Implicaría, también, modificar los arts. 21.2, 23.3, 124.4 e y 125 LRBRL.

36 No así, sin embargo, con otras posibilidades, como la presentación de diversas candidaturas a la alcaldía por parte de una misma formación política o las candidaturas a la alcaldía que no cuenten con el respaldo de por los menos una de las candidaturas que concurren a la elección de concejales, posibilidades que deberían quedar explícitamente excluidas.

37 En este sentido, la delimitación de distritos electorales menores (sean uninominales o plurinominales) tendría como efecto directo incrementar la desproporcionalidad de las elecciones, sin perjuicio de que también puedan reforzar el vínculo entre los electos y el territorio por el cual serían escogidos, pero las mejoras aportadas por este efecto, incluso para las grandes ciudades, nos parecen irrelevantes frente a la distorsión de la proporcionalidad. 
posibilidad de que, mediante una moción de censura (art. 197 LOREG), una votación en plenario pueda tener como resultado la remoción de la persona escogida por la votación popular y su substitución por otra.

Ciertamente, aunque es plausible alegar que así se reducen los instrumentos de fiscalización de la acción del ejecutivo municipal en manos del plenario, también es cierto que, en este ámbito, la moción de censura —en cierta medida, un instrumento impostado de la dinámica parlamentaria - arroja un balance ambiguo. Pues, si este instituto está llamado a posibilitar una salida ante situaciones de bloqueo de la gobernabilidad irreversibles, mediante una solución constructiva, no es menos cierto que no ha tenido una trayectoria precisamente carente de mácula, desde el punto de vista democrático, especialmente en aquellos casos que se han complicado con turbios episodios de transfuguismo.

Así, se podría plantear alternativamente la articulación de algún mecanismo de revocación popular similar al recall, habitualmente presente en los Estados norteamericanos o en Suiza para cargos representativos individuales de elección directa. Con él, un número determinado de electores puede instar a la celebración de una consulta popular en la que se dirima la remoción del cargo representativo cuestionado. Con todo, es indudable que la carencia de precedentes de este tipo de institutos de democracia directa en nuestro derecho político complicaría en exceso su encaje, por lo que no parece la alternativa más plausible ${ }^{38}$. Por otro lado, la resolución de crisis de gobernabilidad irreversibles mediante el uso de la potestad atribuida al gobierno estatal de instar la disolución de corporaciones locales (arts. 61 LRBRL y 183 LOREG) no parece que pueda ser un mecanismo viable, ni siquiera habilitando algún procedimiento especial de petición por parte de la propia Corporación afectada, dado que, en su concepción básica, esta capacidad tiene como objeto erradicar situaciones de quebrantamiento grave de la legalidad ${ }^{39}$. En suma, en el nuevo sistema electoral la remoción del ocupante de la alcaldía, al margen de otras causas forzosas, debería limitarse a una sentencia judicial firme, sin perjuicio de que las leyes pudieran, llegado el caso, compeler al cese una vez alcanzado un momento procesal diferente.

Una reflexión distinta hay que aplicar a la moción de confianza (art. 197bis LOREG), dado que este es un mecanismo de sometimiento voluntario, diseñado como se ha dicho como último recurso para intimar mayorías en plenario, en condiciones de indefinición muy enquistadas y, como también hemos indicado, aplicable exclusivamente a supuestos tasados en la ley (art. 197bis.1 LOREG). Por ello no apreciamos ninguna dificultad en su continuidad como instrumento de último recurso para la alcaldía, en caso de agotar todas las vías para alcanzar un acuerdo en las materias que son vitales para el ente local. Más aún, teniendo en cuenta que su ejercicio es una decisión potestativa del alcalde.

La sucesión del titular de la alcaldía podría decidirse, como antes apuntábamos, tanto mediante un procedimiento especial de voto en plenario como, en caso de adoptarse la idea del «tíquet» electoral, por la persona que hubiese concurrido en calidad de vicepresidente. No obstante, deberían adoptarse las cautelas necesarias para evitar una utilización perversa de esta vía de remoción mediante bloqueos en la gobernabilidad que tengan como objetivo principal la substitución del ejecutivo municipal, quizá planteando algún tipo de limitaciones competenciales para los alcaldes-presidentes resultantes. La denegación de la confianza supondría, de hecho, el agotamiento de la capacidad de propuesta política del gobierno durante el resto del mandato, con un ejecutivo que garantizaría, únicamente, la continuidad de gestión hasta las siguientes elecciones.

\section{Los cambios competenciales y de configuración de órganos municipales}

En el modelo de gobierno local que aquí proponemos, la configuración del plenario debería profundizar en el proceso de «parlamentarización» que ya ha sido abordado, como hemos visto, en las reformas del régimen local de 1999 y 2003, y que implicaría reforzar sus capacidades de deliberación y de control. Esto comportaría, en primer lugar, retirar de la decisión de la asamblea de algunas competencias propias del poder ejecutivo como, por ejemplo, la configuración formal de la gestión de los servicios públicos (arts. 22.2 y y 123.1 k LRBRL), la aceptación de las delegaciones de otras administraciones (arts. 22.2 g y 123.1 j LRBRL), etc. Idéntica consideración merece la aprobación municipal de instrumentos de planificación urbanística derivada (arts. 22.2 c y $123.1 \mathrm{i}$ LRBRL). Es obvio, sin embargo, que determinadas materias, tangentes a la acción ejecutiva, pero de una dimensión política transcendente, deben retenerse en el ámbito de decisión del plenario, como es el caso de las grandes decisiones económicas (ordenanzas fiscales, presupuestos y límites al endeudamiento) o de ciudad (planeamiento urbanístico general y sus modificaciones, etc.).

38 Vid. la aportación de DELGado-IRIBARREN en ARIÑO ORTIZ, GASPAR ET AL. (2008: pp. 50-51).

39 De hecho, esta potestad sólo ha sido utilizada en una ocasión, en 2006, para la disolución del Ayuntamiento de Marbella al detectarse un notorio caso de corrupción sistémica. En relación a este caso y, en general, la naturaleza jurídica de la disolución de Ayuntamientos, vid. PÉREZ FRANCESCH, JoAN LLUís (COORD.) ET AL. (2007). 
Por contra, el alcalde debería perder la condición natural de presidente del plenario (arts. 21.1 c y 122.2 LRBRL), dejando a la asamblea de electos la atribución para escoger, entre cualquiera de sus miembros con la excepción del que ostente la alcaldía, la persona que debe ocupar y ejercer su presidencia; así mismo, el plenario debería dotarse de un reglamento propio ${ }^{40}$. Por otro lado, podría ser positivo abrir la facultad del funcionamiento en comisiones del plenario, actualmente contemplada para los municipios de gran población (art. 122.3 y 4 LRBRL), a un conjunto más amplio de municipios ${ }^{41}$. En este aspecto, aunque se trata de un procedimiento ajeno a nuestra tradición institucional, podría estudiarse la configuración de una comisión especial del plenario, con carácter obligatorio, que actuaría como órgano decisorio para el caso de grandes adjudicaciones municipales, esto es, para la contratación de obras, servicios y suministros, concesiones o enajenaciones de patrimonio por encima de una determinado umbral de valor económico ${ }^{42}$

Como hemos referido antes, es evidente que el modelo que proponemos, con elecciones segregadas para los concejales y para la alcaldía, puede generar una tensa dialéctica entre el poder ejecutivo y la asamblea de electos, en caso de ausencia de mayoría absoluta afín a la candidatura de la persona que ocupe la alcaldía, con episodios concretos de crisis de gobernabilidad graves. Nuestra propuesta asume este riesgo como una forma de equilibrar el fortalecimiento de la autonomía y atribuciones del ejecutivo municipal, concentradas principalmente en un órgano unipersonal, con la pluralidad en la composición del órgano de fiscalización del mismo. Dicho equilibrio debería ser un incentivo poderoso para buscar amplios consensos democráticos entorno a la acción de gobierno municipal. Por otro lado, no es ésta una arquitectura institucional extraña en regímenes con una estricta separación de los poderes legislativo y ejecutivo.

Entre los instrumentos nuevos que nuestro modelo aporta a la dinámica de relación entre los dos órganos fundamentales del gobierno local, cabe recordar el refuerzo de la autonomía respectiva que se deriva de la doble legitimidad en el sistema de elección y la nueva configuración de los instrumentos de fiscalización que pueden derivar en la remoción del alcalde-presidente; podría pensarse, adicionalmente, en la importación de instrumentos de fiscalización usados en la dinámica parlamentaria (las preguntas de control al presidente). Por otro lado, la propia lógica del sistema de elección a dos vueltas impone la necesidad, en algunos casos, de la necesidad de llegar a acuerdos sobre la gobernabilidad con carácter previo a los comicios, obligando así a una mayor transparencia de las intenciones de las formaciones política. Esto ayudaría también a corregir la concepción negativa que, en ocasiones, acompaña los pactos electorales, una creencia que, como señala RoBLES EGEA (1992: pp. 303-304),

«No puede ser más que el resultado de una concepción negativa y errónea del diálogo político, de la implementación de los acuerdos logrados y de los actores que protagonizan tales tareas. En definitiva, de la política misma. Las supuestas implicaciones negativas de la práctica de pactos electorales o poselectorales señaladas por la opinión pública, y también por algunos politólogos, no tienen que ser necesariamente tales. Las alianzas no desembocan ineludiblemente en falta de honestidad o de eficacia y tampoco en inestabilidad de gobierno, como cabría imaginar a primera vista, si bien no cabe suponer con certeza que su existencia sea condición sine qua non para asegurar la perfectibilidad moral de los políticos coaligados ni su eficacia en la gestión, lo que dependerá de muchos otros factores.»

\section{La autonomía del alcalde-presidente en el diseño y designación del «entorno ejecutivo» del gobierno municipal}

Parece coherente que la configuración de un gobierno municipal de carácter presidencialista incorpore una potestad amplia del alcalde para la libre elección de los miembros de su equipo de gobierno, incluida la posibilidad de designar a personas no electas para ocupar una parte significativa de cargos ejecutivos del máximo nivel. En su momento, la reforma de 2003 de la LRBRL estableció esta posibilidad, limitada a un tercio de los miembros de la Junta de Gobierno Local, para las grandes ciudades (art. 126.2 LRBRL), dentro de una línea argumental en la que se primó «el liderazgo claro y diáfano ante la sociedad, lo que exige ejecutivos con gran capacidad de gestión para actuar rápida y eficazmente» ${ }^{43}$. Sin embargo, la STC 103/2013 declaró la inconstitucionalidad de dicha disposición ${ }^{44}$, mediante una fundamentación que exige un examen con cierto detenimiento.

40 Tomando como referencia lo actualmente previsto en el régimen de los grandes municipios (art. 122.3 LRBRL).

41 En principio, cabría pensar que los municipios que accedieran a esta posibilidad deberían contar con un número de concejales que dotase de sentido a la misma. A título orientativo, creemos que sería razonable plantearlo para los municipios con más de 20.000 vecinos ( 21 concejales, art. 179.1 LOREG).

42 En este caso, las reformas en el régimen local debería acompañarse, seguramente, de alguna modificación en la legislación de contratación del sector público.

43 Exposición de motivos de la Ley 57/2003, de 16 de diciembre, de medidas para la modernización del gobierno local.

44 Inconstitucionalidad que se limita única y exclusivamente a la facultad que se reconoce al alcalde para nombrar como miembros de la Junta de Gobierno a personas que no ostenten la condición de concejales.

REALA, n 3, enero-junio 2015, ISSN: 1989-8975 - DOI: http://dx.doi.org/10.24965/reala.v0i3.10241 
Efectivamente, el Alto Tribunal reprochó la inconstitucionalidad del art. 126.2, párrafo segundo, inciso primero de la LRBRL aplicando el razonamiento (FJ 6) de que, a partir de la reforma de 2003, «la Junta de Gobierno local se constituye como un órgano colegiado que asume las competencias administrativas que, en los municipios de régimen común, corresponden al Pleno y al Alcalde, pero también se convierte en un órgano esencial de colaboración en la dirección política del Ayuntamiento pues el alcalde - que conserva la presidencia el órgano colegiado y la capacidad de nombrar y cesar libremente a sus miembros-, comparte la dirección política con la Junta de Gobierno local», con lo cual la habilitación para la designación de miembros no electos de la Junta de Gobierno Local entra en contradicción con el art. 140 CE que, según el TC,

«Atribuye al alcalde y concejales tanto el gobierno como la administración municipal, esto es, y sin perjuicio de la dificultad que puede conllevar a menudo la delimitación de ambas funciones, tanto la alta dirección de la política municipal en lo que supone de adopción de decisiones con criterios esencialmente políticos, como también la suprema dirección de la Administración municipal» (STC $103 / 2013$, FJ 6$)^{45}$.

Sin embargo, el hecho es que, en la referida sentencia, el TC expresó un parecer en apariencia muy distinto al que previamente emitió en la STC 132/2012 para validar «diversos preceptos de la Ley de consejos insulares que atribuyen funciones propias del gobierno y administración de los consejos insulares a unos órganos —los consejos ejecutivos, la direcciones insulares y las secretarías técnicas - cuyos miembros o titulares no es preciso que tengan la condición de electos» (STC 132/2012, FJ 2). Precisamente, el TC subrayó aquí que

«[E]l carácter representativo de los órganos a los que corresponde la dirección política de los entes locales constituye una exigencia inherente a este concepto de autonomía local. Una exigencia que, en el plano normativo, se traduce en la atribución constitucional del gobierno y administración municipal a alcaldes y concejales electos (art. $140 \mathrm{CE}$ ) y del gobierno de las provincias a corporaciones "de carácter representativo" (art. 141.2 CE). Por otro lado, esta misma exigencia es compatible con la existencia, en el seno de esos entes locales, de órganos cuya integración no se encuentre enteramente reservada a los miembros electos de la corporación, al primar en ellos el perfil ejecutivo. En el bien entendido que éstos deberán responder de su acción ante aquéllos, que, precisamente por reunir la condición de órganos representativos, son los únicos facultados para dirigir la acción de las Administraciones locales en ejercicio de ese núcleo de la autonomía local que, según dijimos en la STC 193/1987, de 9 de diciembre, FJ 4, "consiste, fundamentalmente en la capacidad de decidir libremente, entre varias opciones legalmente posibles, de acuerdo con un criterio de naturaleza esencialmente política (STC 4/1981, fundamento jurídico 3)". Esta compatibilidad figura, igualmente, en la propia Carta europea de la autonomía local anteriormente mencionada, en cuyo art. 3.2 se señala que el derecho al autogobierno local "se ejerce por Asambleas o Consejos integrados por miembros elegidos por sufragio libre, secreto, igual, directo y universal y que pueden disponer de órganos ejecutivos responsables ante ellos mismos"» (STC 132/2012, FJ 4).

Consciente de la similitud entre ambos asuntos, el TC ya referenció en la STC 132/2012 (FJ 2) la posible discrepancia entonces de su decisión con la que podía disponer para la cuestión específica de la Junta de Gobierno Local más adelante. Esta mención se plasma en la STC 103/2013 (FJ 6), donde se argumenta que,

«El principio representativo constituye el fundamento de la autonomía local y por tanto es predicable de todas las entidades locales constitucionalmente garantizadas, este principio ha sido consagrado para los municipios con una intensidad especial, mediante una regulación bastante más minuciosa, que contrasta con la menor densidad normativa con que la norma fundamental lo ha recogido para islas y provincias».

45 A criterio del máximo intérprete constitucional, «[e]n definitiva, el art. 140 CE otorga una especial legitimación democrática al gobierno municipal, tanto en su función de dirección política, como de administración, que contrasta, sin duda, con el diseño que la propia Constitución establece para el Gobierno del Estado (art. 97 y 98 CE). Un plus de legitimidad democrática, frente a la profesionalización, que, en todo caso, debe ser respetada por el legislador básico al configurar ese modelo común de autonomía municipal». Cabe recordar, sin embargo, que la STC 103/2013 contó con el voto particular suscrito por los magistrados Andrés Ollero y Francisco Pérez de los Cobos, en el cual se discrepaba del sentido del parecer mayoritario, en particular en este punto, por entender que al deducir del art. 140 CE «que solo estos [el alcalde y los concejales] puedan asumir toda imaginable función de "gobierno y administración" no solo desafía el sentido común, ante la obvia existencia de funcionarios locales, sino que implica atribuirse el monopolio de qué se entiende por gobierno y administración, despojando al legislador de toda capacidad de desarrollo al respecto». 
En esencia, pues, la ratio decidendi que aplica el Alto Tribunal en la sentencia de 2012 se fundamenta en los siguientes elementos: (1) la menor precisión del texto constitucional sobre la administración de las entidades locales supramunicipales, en relación a los ayuntamientos, (2) la peculiariedad que otorga a la regulación de los consejos insulares derivada de la llamada al correspondiente texto estatutario que se contiene en el art. 41.3 $\operatorname{LRBRL}^{46}$ y (3) la ausencia de vulneración del principio representativo inherente a la autonomía local dado que se preservan todas las potestades decisorias y el control político del Pleno del consejo insular, integrado solamente por miembros electos ${ }^{47}$.

El argumento distintivo del Alto Tribunal no carece, sin embargo, de puntos objetables. En primer lugar, cabe subrayar que la doctrina constitucional ha establecido en otras ocasiones, singularmente la STC 31/2010 (FJ 36), la situación jerárquicamente subordinada de las disposiciones estatutarias respecto de la normativa básica estatal, lo cual invalidaría la apelación al texto estatutario para habilitar cualquier especificidad insular en el régimen local que contraviniese la base estatal ${ }^{48}$. Además, si se conviene que el gobierno y la administración de los entes locales deben estar exclusivamente en manos de las personas electas (art. 140 CE) es difícilmente sostenible que los gobiernos provinciales (o los insulares como institución asimilada), aunque encomendados a «corporaciones representativas» (art 141.2), puedan integrar en sus órganos personas no electas ya que éste carácter forma parte consubstancial de la naturaleza representativa atribuida a dichas corporaciones. De hecho, la calificación de meramente ejecutivas de las funciones encomendadas a los órganos cuestionados resulta más que cuestionable cuando se comparan los contenidos de la Ley balear 8/2000 (arts. 12 y 13) con las funciones asignadas a la Junta de Gobierno Local. Finalmente, no parece admisible que la peculiaridad insular o estatutaria pueda sustentar la disponibilidad autoorganizativa de los Consejos Insulares en detrimento de lo establecido en las bases estatales ${ }^{49}$.

A pesar de los argumentos que cuestionan la jurisprudencia constitucional en esta materia, lo cierto es que el fallo de la STC 103/2013 limita significativamente la libertad del alcalde para configurar un equipo de gobierno local, algo que en un contexto presidencialista, como el que aquí se propugna, sería dócilmente armonizable. Además, en un panorama más amplio de la configuración de los entes locales, también reduce las posibilidades de avanzar hacia un modelo más profesionalizado y gerencial del gobierno ejecutivo local, como parece ser la tendencia prevalente en las concepciones institucionales y de los principales partidos, claramente deslindado de las funciones políticas y representativas que deberían asignarse a las personas electas.

Frente a ello sólo se nos ocurren dos vías de resolución. La primera, la más obvia, directa y formalmente exigente, es la reforma del art. 140 CE. Por el contrario, la vía alternativa plantearía, en paralelo, la supresión de la Junta de Gobierno Local, la transferencia de sus competencias a la figura del Alcalde-Presidente (modificación de los arts. 23.2 y, especialmente, el 127.1 de la LRBRL) y la creación de un nuevo órgano colegiado de gobierno muy claramente definido como ejecutivo y abierto a designados no electos. Sus función básica debería centrarse en asistir a la alcaldía en el ejercicio de sus atribuciones e incluso contemplar la delegación de las más políticas de ellas restrictivamente para los miembros de dicho órgano que ostentasen, simultáneamente, la condición de

46 «[E]I art. 141.4 CE confiere al legislador estatutario un amplio margen de decisión para regular el régimen jurídico de los consejos insulares como administración propia de la isla y a su vez como "instituciones autonómicas propias" [art. 147.2 c) CE], en consideración a la singularidad del fenómeno insular, de la misma manera que hemos reconocido que la finalidad de "atender a la singularidad del sistema institucional" establecido por determinadas Comunidades Autónomas en sus Estatutos de Autonomía hay que vincularla a la “peculiaridad” de esas Comunidades (STC 31/2010, de 28 de junio, FJ 141, que a su vez cita la STC 109/1998, de 21 de mayo, FJ 7)» (STC 132/2012, FJ 4).

47 «En efecto, ninguna de las funciones legamente atribuidas a esos órganos ejecutivos — consejos ejecutivos, direcciones insulares y secretarías técnicas - les permite adoptar decisiones basadas exclusivamente en criterios de naturaleza esencialmente política, que, como ya hemos apuntado con anterioridad, constituyen el núcleo esencial de la autonomía local, correspondiéndoles tan solo la ejecución de las normas y directrices aprobadas por el Pleno del consejo insular, dirigiendo o gestionando los correspondientes servicios administrativos» (STC 132/2012, FJ 4).

48 Estos elementos se destacan en el voto particular a la STC 132/2012 suscrito por los magistrados Luis Ignacio Ortega y Adela Asúa «Como a nadie se le escapa, estamos ante una construcción doctrinal relativa a la relación entre el legislador básico de régimen local, y los Estatutos de Autonomía, en la que por vez primera se realiza, sin, a mi juicio, un suficiente respaldo de construcción jurídica y sin la advertencia del salto interpretativo que ello supone, una excepción constitucional al régimen local basada en el hecho insular. (...) [L]a correcta aplicación del art. 41.3 LBRL había de llevar entonces a la confrontación de los preceptos legales impugnados por asignar a no electos funciones propias del gobierno y administración de la isla con las previsiones de la Ley reguladora de las bases de régimen local relativas a la organización de las Diputaciones provinciales (arts. 32 a 35, muy en especial, este último, relativo a la Junta de Gobierno integrada por el Presidente y un número de Diputados no superior al tercio del número legal de los mismos, nombrados y separados libremente por aquél, dando cuenta al Pleno). Como puede inferirse sin dificultad las conclusiones a las que se llega tras este análisis son radicalmente contrarias a las alcanzadas por la Sentencia de la mayoría».

49 Como expresa el voto particular a la STC 132/2012 de los magistrados Luis Ignacio Ortega y Adela Asua: «la pretensión de dar a entender que la organización de los consejos es disponible para el Estatuto porque lo permite la Ley reguladora de las bases de régimen local, cuando lo que de esta última cabe calificar como susceptible de ser afectado por la regulación estatutaria es, como derechamente se desprende de su tenor literal, estrictamente, lo relativo a las competencias de los consejos insulares, permitiendo a éstos la asunción de competencias autonómicas en términos similares a los que este Tribunal tuvo ocasión de examinar en la STC 31/2010, FFJJ 37 y 100». 
concejales. Se recuperaría así, en parte, el espíritu primitivo de la Comisión de Gobierno, en tanto que órgano colegiado puramente delegado de la presidencia local y de asistencia en la toma de decisiones, lo cual parece adecuarse mejor al carácter de una alcaldía presidencialista.

\section{La modulación temporal de las reformas electorales}

La polémica que rodeó la tantas veces repetida propuesta del Gobierno gravitó en torno a la manifiesta intención de su promotor de aplicarla en los comicios electorales de 2015. Como hemos expuesto, el análisis más pormenorizado no tan sólo evidencia que no se trata de una reforma neutral — difícilmente encontraríamos una modificación del sistema electoral que lo fuese-, sino que aporta determinadas ventajas claras a la opción política que la postula, incluido el incremento de probabilidades de preservar las alcaldías de determinadas ciudades que esta formación considera claves.

Seguramente, ninguna reforma electoral podrá esquivar las acusaciones de aprovechamiento en beneficio propio por parte de aquellas formaciones que la impulsen o la apoyen, especialmente si éstas ocupan el gobierno. Ahora bien, la situación sería distinta en caso de existir una ordenación del diferimiento necesario entre la aprobación de dicha reforma y el inicio de su aplicación práctica. Este compromiso, que debería tener una sólida vocación de permanencia y afectaría al conjunto de niveles de gobierno, no debería reflejarse en una ley ordinaria, ni siquiera en una orgánica, sino que debería constitucionalizarse, siendo la opción más práctica la modificación (adición) del artículo 81 de la misma. En cuanto al plazo de diferimiento, lo más razonable sería situarlo por encima de dos años.

\section{CONCLUSIONES}

El modelo de gobierno municipal en España ha sido objeto de diversas reformas, que pretendían corregir las principales disfunciones observadas en el ejercicio práctico, en la línea combinada de diferenciar los ámbitos de actuación de los órganos que lo integran (plenario y ejecutivo municipal), a la par que "gerencializar» la administración ejecutiva de los ayuntamientos. Sin embargo esta ardua tarea en el ámbito institucional no ha venido acompañada de una acción parecida en el sistema electoral, donde se evidencian diversas carencias en materia de representatividad y gobernabilidad de las instituciones electas. Además, por razones de proximidad y personalización de las formaciones políticas locales, existe una demanda insatisfecha de elección directa, por parte de los vecinos, de la persona que debe dirigir el gobierno municipal.

En un contexto de crisis de legitimidad de las instituciones de la democracia española, una reforma del sistema electoral municipal, entre otras acciones, contribuiría sin duda a la mejora de la calidad democrática de un sistema seriamente cuestionado. Algunas propuestas recientes en este sentido (la del Gobierno en 2014, pero también la del PSOE en 1998 y la del Consejo de Estado de 2009), ponían el énfasis en corregir las deficiencias de gobernabilidad, mediante sistemas electorales que primen, en cada municipio, las opciones mayoritarias. No obstante, no parece que esta cuestión se encuentre en un lugar preferente en la jerarquía de preocupaciones de la ciudadanía, más exigente si cabe en los aspectos de representatividad y fiscalización.

La opción reproducida en este trabajo parte de instaurar un sistema presidencialista de gobierno local, con elección separada, por un lado, de la persona titular de la alcaldía y, por otra, de los concejales. Este sistema exige reequilibrar, mediante una modificación de la arquitectura institucional local, la asignación de atribuciones entre un poder ejecutivo reforzado, en términos de autonomía y legitimidad, y la representatividad y funcionalidad de una asamblea de electos, dedicada a la dirección política del gobierno municipal y la fiscalización del ejecutivo. Por lo demás, el conjunto de la reforma plantea diversas dificultades salvables de índole constitucional, las cuales son igualmente analizadas en el presente artículo.

\section{BIBLIOGRAFÍA}

ARIÑO ORTIZ, GASPAR ET AL. (2008): «Encuesta sobre el régimen electoral», Teoría y Realidad Constitucional, núm. 22, Madrid: UNED, pp. 11-91.

BarberÁ, PABlo (2010): «Voting for Parties or for Candidates? The Trade-Off Between Party and Personal Representation in Spanish Regional and Local Elections», Revista española de investigaciones sociológicas, núm. 132, pp. 35-63.

BENOIT, KENNETH (2004): «Models of electoral system change», Electoral Studies, núm. 23, pp. 63-389.

BOIX, CARLES (1999): «Setting the Rules of the Game: The Choice of Electoral Systems in Advanced Democracies», The American Political Science Review, Vol. 93, Núm. 3 (Sept.), pp. 609-624. 
BOteLLA, JOAN (1992): «La galaxia local en el sistema político español», Revista de Estudios Políticos, núm. 76, pp. 45-160.

CAAMAÑO, FRANCISCO (2004): «Autonomía local y Constitución. Apuntes para un debate», Criterios. Revista de pensamiento político y social, núm. 4 (noviembre), pp. 25-60.

COMISIÓN DE ESTUDIOS DEL CONSEJO DE ESTADO (2009): Informe del Consejo de Estado sobre las propuestas de modificación del régimen electoral General, Madrid: Consejo de Estado. [Disponible on line en: http://www.consejoestado.es/pdf/REGIMEN-ELECTORAL.pdf (consultado el 30.12.2014)]. La parte dedicada a los procedimientos electorales locales se encuentra en las pp. 243-271.

Cosculluela Montaner, L. (1988): «Las elecciones locales», en MuÑoz MACHAdo, S.: Tratado de Derecho Municipal, Madrid: Civitas, pp. 687-734.

De CARRERAS, FrancesC (2014): «Elección directa: ahora no», El País, 19.08.2014. Disponible on-line: http:// politica.elpais.com/politica/2014/08/19/actualidad/1408472011_140198.html [Consultado el 30.12.2014].

GARCíA FERNÁNDEZ, JAVIER (2014): «La ruptura del consenso electoral», El País, 2.09.2014 (disponible on-line: http://elpais.com/elpais/2014/08/27/opinion/1409162319_645988.html [Consultado el 30.12.2014]).

MÁRQUEZ CRUZ, GUILLERMO (1994): «Bases para el estudio de la inestabilidad política de los gobiernos locales», Revista de Estudios Políticos, núm. 86, Madrid: Centro de Estudios Político y Constitucionales, octubre-diciembre, pp. 261-311.

MÁRquez CRUZ, GUILlermo (1999): «Veinte años de democracia local en España: elecciones, producción de gobierno, moción de censura y élite política (1979-1999)», Revista de Estudios Políticos, núm. 106, octubrediciembre, pp. 289-334

MÁRQUEZ CRUZ, GUILLERMO (2003): «Marco metodológico para el estudio de las coaliciones políticas en los gobiernos locales en España», Política y Sociedad, Madrid: Universidad Complutense de Madrid, Vol. 40, Núm. 2, pp. 157-178.

Medina GuerRero, MANUel (2014): «Municipalismo y profundización democrática», Temas para el debate, núm. 232 (marzo), pp. 39-40.

MONTERO, JOSÉ RAMÓNY RIERA, PEDRO (2009): «El sistema electoral español: cuestiones de desproporcionalidad y de reforma», AFDUAM, núm. 3, pp. 225-270.

PÉREZ FRANCESCH, JOAN LLUís (COORD.) ET AL. (2007): “Disolución de los Ayuntamientos en España y corrupción sistémica. Aproximación al «Caso Marbella» y comparación con la normativa italiana en materia de disolución en supuestos de emergencia extraordinaria", Revista de Estudios de la Administración Local y Autonómica (REALA), núm. 305, septiembre-diciembre, pp. 299-324.

RIDAO, JOAN (2014): «La crisis de legitimidad de la democracia representativa en España: aventurando algunas soluciones», El Cronista del Estado social y democrático de derecho, núm. 48 (noviembre), pp. 18-23.

RIERA, PEDRO (2011): «Closed party list», en COLOMER, JOSEP M. (ED.): Personal representation. The neglegted dimension of electoral systems, Colchester: ECPR Press, pp. 53-77.

ROBLES EGEA, ANTONIO (1992): «Reflexiones sobre las coaliciones políticas», Revista de Estudios Políticos, núm. 77, Madrid: Centro de Estudios Político y Constitucionales, julio-septiembre, pp 303-320.

SÁNCHEZ SÁEZ, ANTONIO JOSÉ (2006): «El principio democrático en la Administración Local: la elección directa del alcalde y las potestades de autoorganización y sancionadora», Revista de Estudios de la Administración Local y Autonómica, Madrid: INAP, núm. 302, pp. 185-210

SANTOLAYA, PABLo (2009): «Estudio introductorio al Informe de la Subcomisión creada en el seno de la Comisión Constitucional sobre las posibles modificaciones del Régimen Electoral General, de 28 de junio de 2010», Cuadernos de Derecho Público, núm. 36, enero-abril, pp. 221-230.

UBASART-GONZÁLEZ, GEMMA (2012): «Municipalismo alternativo y popular ¿Hacia una consolidación de las tesis del nuevo localismo y la politización del mundo local?», Revista de Estudios Políticos, núm. 157, julio-septiembre, pp. 135-162.

Vallés Casadevall, Josep María y Bosh Guardella, Agustí (1997): Sistemas electorales y gobierno representativo, Barcelona: Ariel. 
